Instituto de Estudios Urbanos y Territoriales, Pontificia Universidad Católica de Chile, Centro de Desarrollo Urbano Sustentable.

aLicenciada en Historia. PhD.

Trabajo financiado por proyecto Conicyt/Fondap/15110020

Recibido el 3 de julio de 2015, aceptado el 7 de diciembre de 2015.

Correspondencia a: Macarena Ibarra PhD Instituto de Estudios Urbanos

y Territoriales, Pontificia Universidad Católica de Chile. El Comendador 1916 Providencia, Santiago de Chile. Código postal: 7520245 . Teléfono: 223547759 mibarraa@uc.cl.

\section{Higiene y salud urbana en la mirada de médicos, arquitectos y urbanistas durante la primera mitad del Siglo XX en Chile}

\author{
MACARENA IBARRA ${ }^{\mathrm{a}}$
}

\section{Hygiene and urban health as seen by physicians, architects and planners during the first half of the twentieth century}

Physicians took part in the promotion of public policies that regulated urban and architectural work, before engineers, architects, planners, and even before the State had a chance to take part in the formulation of such policies. Starting in the late nineteenth century, and especially during the first decade of the twentieth century, the State began to lead on the issue of hygiene and public health. This paper focuses on the role of these professionals, who generated debates within their respective disciplines, or provided-as ministries, public servants or consultantstechnical knowledge to the central government. These debates are still relevant for two reasons. First, they serve as reminders of the way in which the voice of these professionals was crucial not only within their respective disciplines, but also in order to place the issue of hygiene and public health on the agenda and to promote public policies related to the urban environment and its population. Secondly, these debates represent a challenge to current planners, as this historic context provides insight on the complex relationship between public health and planning, which hitherto has received little attention.

(Rev Med Chile 2016; 144: 116-123)

Key words: Hygiene; Public health; Urban health.

\footnotetext{
L
} a higiene y la salud pública patrocinaron el desarrollo de políticas urbanas en la sociedad industrial de Chile y el mundo. La higiene, que apareció particularmente en el mundo urbano ${ }^{1}$ como respuesta a las altas tasas de mortalidad, fue ideal dinamizador de cambios culturales ${ }^{2}$, permeó la arquitectura, planteó desafíos en la infraestructura sanitaria (la extensión de agua potable, la incorporación del alcantarillado y la gestión de las basuras), influyó en la expansión de la ciudad y apareció como una dimensión de lo que a fines del siglo XIX se concibió como moderno. De ahí que la higiene y la salud pública -tal como la vivienda, denunciada desde los insa- lubres ranchos y conventillos- fueran los ejes de las grandes cirugías urbanas que se iniciaron a partir de fines del siglo XIX, en vísperas que el problema urbano, entonces en manos de la Beneficencia, pasara a ser parte de la agenda del Estado ${ }^{3}$.

Mientras el estudio de la vivienda insalubre ha acaparado la atención de la historiografía, este artículo examina el debate sobre higiene y salud urbana en relación a la escuela decimonónica y a la industria del siglo XX. Al promediar el siglo, parte de las respuestas del Estado frente al problema urbano, que ya contaba con una administración sanitaria, se encaminó hacia la construcción de consultorios y hospitales acorde a las dimensio- 
nes que adquirían ciudades de creciente carácter industrial.

El estudio recoge diversas fuentes documentales entre las que se encuentran publicaciones periódicas (Revista de Asistencia Social y Revista de Instrucción Primaria); publicaciones institucionales (Boletín del Servicio Nacional de Salud); reglamentos en materia urbana, legislación sanitaria, registros de asociaciones profesionales; cátedras universitarias, discusiones parlamentarias $\mathrm{y}$ discursos presidenciales en la materia.

\section{Higiene y salud urbana en la agenda pública}

En Chile, el despertar del Estado en materia de higiene y salud pública surgió tras el brote de cólera en 1886. Aquel episodio suscitó la creación de la Comisión de Higiene Pública (1891) que, un año más tarde, dio origen al Consejo Superior de Higiene Pública. Dicho consejo fue la primera autoridad central con atribuciones en la coordinación de políticas mientras se legislaba para enfrentar el creciente problema médico-social que afectaba al país. En conjunto con el consejo, se creó el Instituto de Higiene (Figura 1), el cual contaba con una sección de higiene y estadística, una sección de química y otra sección de microscopía y bacteriología. Sus servicios, de carácter técnico, tenían que ver con estudios, análisis y centralización de datos relevantes en relación a la salud pública. Dicho instituto generó una intensa actividad en materia de higiene, química y demografía y su importancia radicó en formar a una generación de médicos especializados. Adicionalmente, se creó el Desinfectorio Público (Figura 2), cuya labor se hizo más eficiente a raíz de la ley de 1899 , la cual establecía como obligatoria la desinfección de habitaciones u objetos contactados con enfermedades declaradas, entonces, como infecciosas: cólera, fiebre amarilla, peste bubónica, difteria, viruela, tifus, escarlatina y lepra ${ }^{4}$.

Al iniciar el siglo XX, el discurso higienista clásico, representado por la tradición miasmática que se ocupaba del medio y de la ciudad, se enfrentó a un nuevo paradigma: la microbiología. En Chile, la institucionalización de la administración sanitaria también asumía el encuentro de estas dos tradiciones, donde el desinfectorio público convivió con un centro de serología que recogía las nuevas formas de la ciencia para combatir los microbios. Ilustrativo de este cambio fue la inauguración del Instituto de Bacteriología (1929) -antecesor del

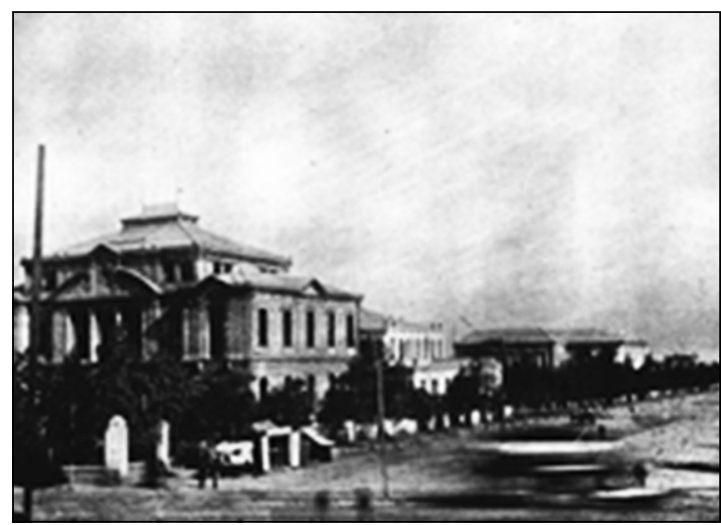

Figura 1. Vista panorámica del Instituto de Higiene, 1910. Memoria Chilena.

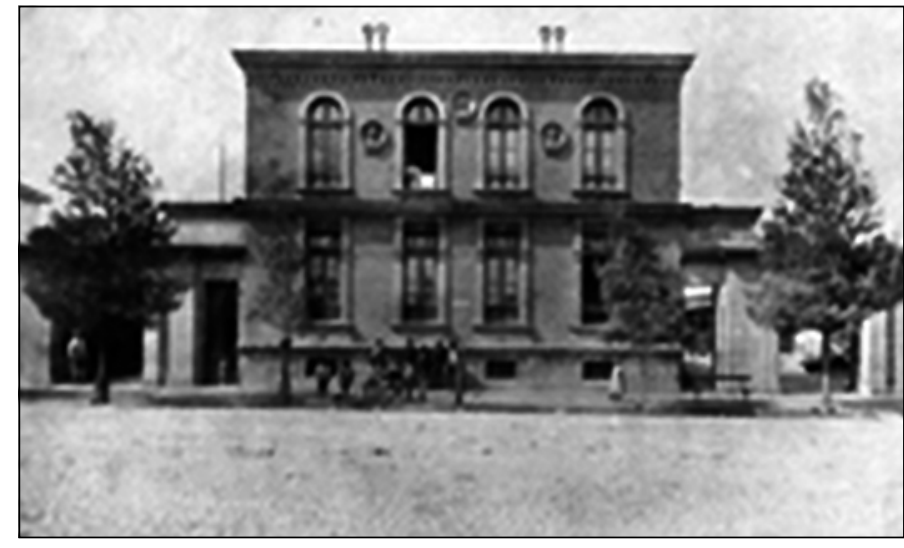

Figura 2. Desinfectorio Público, 1910. Memoria Chilena. 
Instituto de Salud Pública-, instalado en los edificios que ocupó el Instituto de Higiene y que, en 1947, fue trasladado a una moderna construcción en Ñuñoa.

La trayectoria del rol del Estado en materia de higiene se vio reflejada también en las carteras de gobierno. El Consejo Superior de Higiene y el Instituto de Higiene surgieron como dependientes del Ministerio del Interior. La importancia que este asunto adquirió se reflejó en la creación de la Sección de Higiene que, en 1907, se introdujo en la cartera de dicho ministerio. Posteriormente, en 1924, la conformación del Ministerio de Higiene, Asistencia, Previsión Social y Trabajo ${ }^{5}$-origen de la cartera de Salud- obedeció a la necesidad de mejorar las condiciones sanitarias y reducir la excesiva mortalidad. Tal fue reorganizado como Ministerio de Bienestar Social en 1927.

Además de los avances institucionales, publicaciones, congresos y cátedras universitarias, contribuyeron a instalar esta problemática en la agenda de profesionales. Así, la preocupación por la higiene urbana no sólo fue exclusiva del círculo médico. De interés resulta la incorporación de la dimensión de la salud en la construcción de edificios presentada por el arquitecto Ricardo Larraín Bravo en los tres volúmenes de su obra más reconocida: La higiene aplicada a las construcciones (1909) (Figura 3). En su manual -recomendado para arquitectos, ingenieros y constructores-, Larraín examinaba reglas y procedimientos a los que se debían someter los edificios con el fin de incorporar el máximo de cualidades sanitarias, "tan desconocidas aún en Chile" 6 . En la emblemática población Huemul I (1911), Larraín organizó 166 viviendas obreras de fachada continua alrededor de patios, lo que permitía la entrada de luz al interior de los recintos e incorporó las reglas de la higiene pública y privada. El moderno conjunto contó con servicio de alcantarillado y agua potable, además de equipamiento adicional ${ }^{7}$.

El cruce de nociones de higiene entre profesionales penetró las cátedras impartidas para su propia formación. Mientras médicos proponían la construcción de edificios higiénicos y la reparación de los existentes, se sumaron profesionales como el propio Larraín Bravo, quien ofreció cátedras de Arquitectura en la Universidad de Chile, y de Higiene Aplicada a las construcciones en la Universidad Católica de Santiago. En ellas, Larraín Bravo entendió la higiene tanto en el ámbito personal y doméstico como público, para lo cual entregaba nociones de anatomía y se refería a los grandes factores de salubridad ${ }^{8}$.

Otros cursos que recogieron los ideales de la higiene contribuyeron a la formación de profesionales en esta materia. Cabe citar el Curso de construcción de Urbano Mena Concha, el cual incorporaba las condiciones de desagüe y accesorios para asegurar el saneamiento de edificios según su destino ${ }^{9}$, mientras las cátedras de medicina también exhibían preocupaciones por la higiene pública. El médico Jorge Calvo Mackenna en su Curso sobre saneamiento de las poblaciones, planteaba como fundamental el conocimiento de las condiciones del medio y buscaba adoctrinar sobre la higiene haciendo especial énfasis en el recurso del agua ${ }^{10}$.

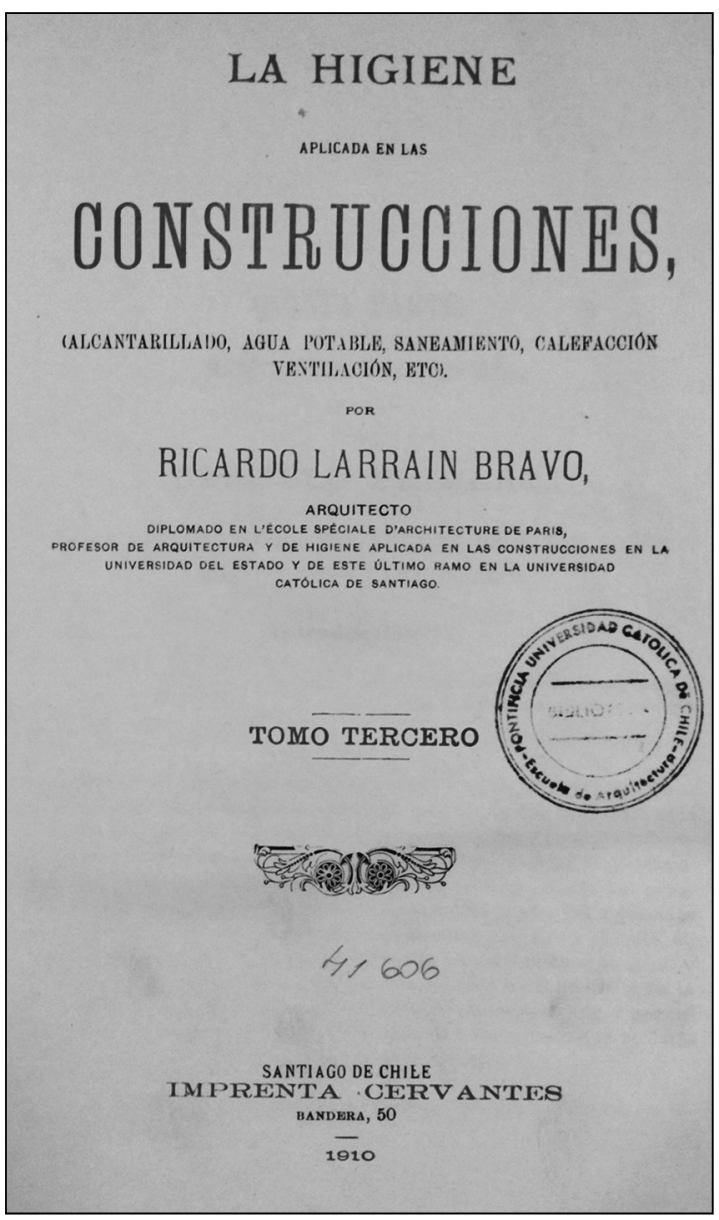

Figura 3. Portada "Higiene aplicada a las Construcciones" de Ricardo Larraín Bravo. Colección propia. 


\section{Higiene en las escuelas}

Aunque la historiografía se ha concentrado en las conquistas de la higiene en lo referido al equipamiento urbano y a la construcción de vivienda social desde inicios del siglo XX -con la pionera ley de 1906-, una mirada a las escuelas primarias públicas en Santiago permite reconocer los aportes de estos profesionales, mientras testifica la naciente regulación en materia de construcción higiénica que se inició ya en la administración del Presidente José Manuel Balmaceda (1886). En este contexto, correspondió a arquitectos recoger en su práctica los protocolos higiénicos que se comenzaban a plantear.

Médicos entregaron fundamentos técnicos y preceptos higiénicos que los edificios escolares debían cumplir. El experto en salud pública, Ricardo Dávila, publicó una serie de indicaciones sobre la construcción de escuelas higiénicas, analizando los preceptos que se debían incorporaren edificios, en relación al menaje, al sistema de enseñanza, al régimen interno y a la higiene personal ${ }^{11}$. En una línea similar, Tomás Ríos denunció el escaso número de escuelas construidas con ese propósito, lo que explicaba la carencia de elementos básicos: circulación del aire, luz y temperatura ${ }^{12}$. Para Ríos, la higiene no era sólo el arte de conservar la salud, sino también el arte de perfeccionarla física y moralmente y, por tanto, la asignatura de educación física debía ser obligatoria ${ }^{13}$.
La doctora Eloísa Díaz, quien fuera Inspectora Nacional de Escuelas, instó a incrementar la superficie de patios y a construir gimnasios, especialmente en las escuelas elementales. Sostenía que los ejercicios debían desarrollarse en galpones adecuados, mientras consideraba perjudicial para la salud "...que estos ejercicios se hagan en patios húmedos en el invierno y al rayo del sol en el verano"14. En uno de sus informes destacaba que "el oxígeno del aire enriqueciendo la sangre, promueve en todos los aparatos una excitación fisiológica notable, y así la nutrición se hace más completa"15 (Figura 4).

No obstante estos avances, hacia 1902 sólo 5 de las 121 escuelas primarias públicas en Santiago funcionaban en edificios construidos especialmente con ese fin; las otras 116 escuelas aún lo hacían en edificios sin preceptos higiénicos ${ }^{16}$. Así, en medio de los esfuerzos por modernizar la capital chilena al iniciar el nuevo siglo, la higiene escolar se mantenía como una deuda por saldar.

\section{Higiene en las industrias}

Avanzado el siglo XX, la incipiente industrialización y la expansión de las ciudades exigió al Estado acoger nuevas atribuciones -antes municipales- del desarrollo local ${ }^{17}$. Aun cuando la administración sanitaria fue creada a partir de1892, en la década de 1930 cambió la manera de entender

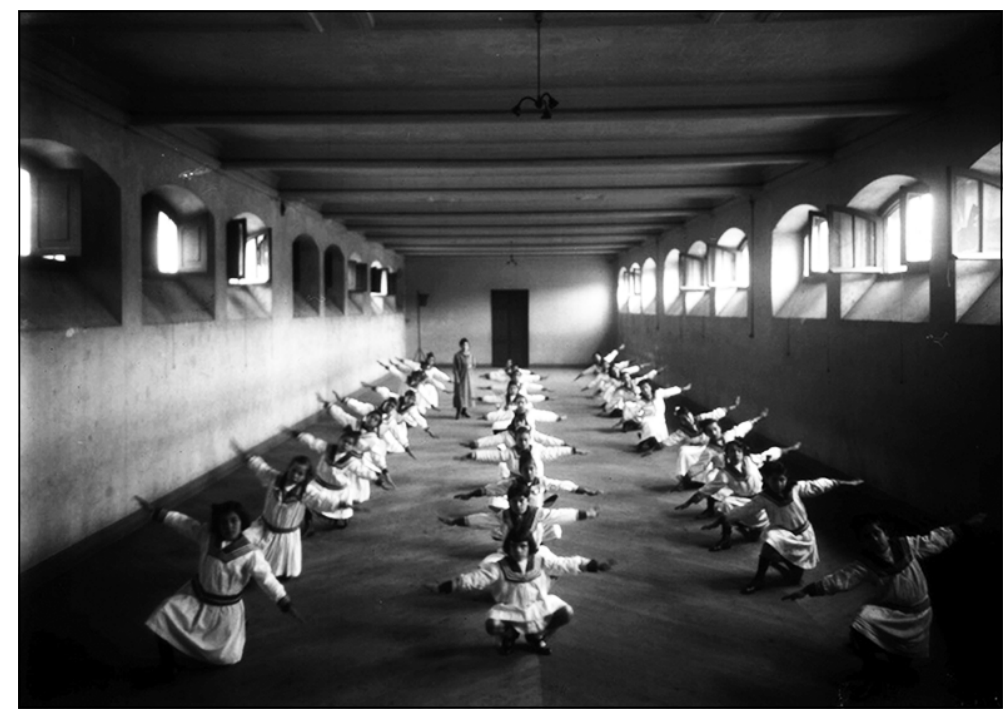

Figura 4. Imágenes Escuela Primaria Moderna. Museo Histórico Nacional, Santiago. 
la salud pública. En 1936, el I Congreso de Beneficencia enfatizó el cambio desde una concepción filantrópica sobre las prestaciones asistenciales a sectores indigentes, hacia un protagónico rol del Estado. Clave fue el Consejo Superior de Salubridad Pública, creado en 1934, con el fin de asistir al Ministro de Salubridad en las tareas de sanitización. Por su parte, el Ministerio del Interior se encargaba del sistema de alcantarillado y de agua potable $y$, reafirmando la preocupación de la higiene y de la salud en torno a la industria, no era coincidencia que el Ministerio del Trabajo promoviera campañas de higiene y de salud pública ${ }^{18}$.

Animados por tales conceptos, médicos, arquitectos y urbanistas, contribuyeron a diagnosticar los problemas de salubridad que enfrentaban las ciudades chilenas. Pese a que en Santiago y en su periferia el servicio de alcantarillado había mejorado el estado de barrios altamente densos, el censo de 1933 indicaba que 65\% de los conventillos se encontraban en deplorables condiciones sanitarias debido a la falta de luz, agua y alcantarillado. De acuerdo a la Dirección General de Sanidad, sólo $30 \%$ de la población chilena se beneficiaba de agua potable y sólo $20 \%$ contaba con servicio de alcantarillado ${ }^{19}$. Pese a una disminución de las tasas de mortalidad infantil, éstas eran aún alarmantes. El poco conocido dato que situaba, en 1933, a Concepción como la ciudad con más alta tasa de mortalidad infantil en el mundo occidental, con 238 muertes por mil, releva aún más este panorama. De hecho, las cifras señalan que “en 1933, la mortalidad infantil alcanzaba a 232 por mil nacidos vivos, hijos casi todos de padres enfermos, alcohólicos y malnutridos"20.

Pese a que las mejoras materiales no lograban reducir la mortalidad, en la década de 1940 ésta ya decrecía ${ }^{21}$. Esto se debió, en parte, al rol de instituciones emblemáticas como la Caja de Seguro Obrero creada en 1924 (Figura 5) y a la Sección de Madre e Hijo, primera institución social y médica del país. También contribuyeron las Gotas de Leche, ubicadas en áreas centrales y accesibles de barrios obreros e industriales, concebidas como entidades a cargo de proteger la salud de los niños.

Y si, hacia el final del período, la noción de higiene parecía agotarse ante el desarrollo de la medicina clínica, médicos, arquitectos y urbanistas alinearon sus debates y propusieron nuevas respuestas, bajo un concepto que denominaron "higiene industrial". Tal concepto, definido por arquitectos, incorporó nociones de ventilación, temperatura, humedad, luz, edificios privados y públicos, exámenes médicos preliminares, prevención de accidentes laborales y trabajo femenino. Así, el concepto de "higiene industrial" admitía, por un lado, la creciente industrialización y la consecuente expansión de ciudades y, por otro, seguía reuniendo a profesionales y al Estado en torno a una preocupación compartida.

\section{Criterios de consultorios y hospitales}

A partir de 1930 cambiaron los programas médicos, los criterios de organización hospitalaria y de localización, con la inclusión de principios funcionalistas de la arquitectura moderna, tanto en propuestas de estructuras tipológicas, como en la zonificación a la que obedeció la construcción de edificios ${ }^{22}$.

Aunque ciertas epidemias habían desaparecido, Santiago celebró sus cuatrocientos años, en 1941, con graves problemas de salud pública a raíz de la

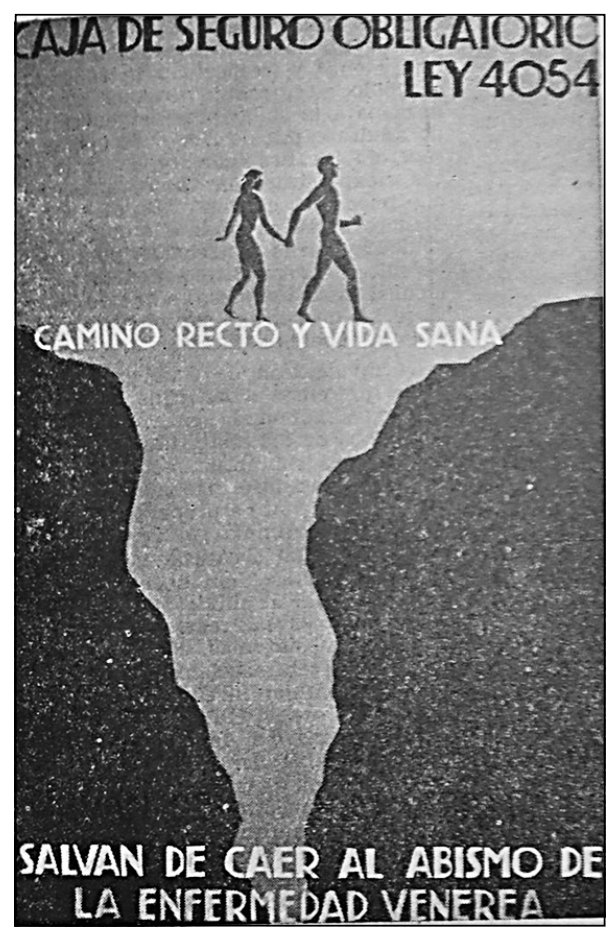

Figura 5. Afiche Caja del Seguro Obligatorio. Boletín Médico de la Caja de Seguro Obligatorio 1936 (1): 32 Colección propia. 
tuberculosis y fiebre tifoidea, mientras aparecían con mayor frecuencia las enfermedades "profesionales o laborales". Tales enfermedades -vinculadas al trabajo fabril- originaron la radiología y dieron inicio a un nuevo programa arquitectónico. Así, las técnicas diagnósticas fueron incorporadas en el abordaje salubrista de las enfermedades sociales, equipamientos y procedimientos, reconfigurando recintos, formas de circulación de pacientes y sistemas de archivo, dando origen a edificios con nuevas cualidades.

La aplicación de la penicilina en la década del cuarenta transformó no sólo a la farmacología y a la medicina sino también el escenario urbano. En Chile, el abandono de los grandes sanatorios dejó camas libres fuera de la entonces periferia urbana, tal como el Hospital Sótero del Río. Esto explicó la proliferación de centros de atención primaria, donde podían tratarse pacientes gracias a la medicación y no al aislamiento.

Los avances en materia de higiene, salubridad y salud pública se vieron reflejados en la nueva infraestructura para la atención primaria: la construcción de modernos edificios como consultorios cambiaron la escala en sectores de la ciudad. Por citar algunos casos, en Santiago se construyó un consultorio en calle Maruri (1936-9), edificio de moderna estructura que llegó a ser el hospital más alto de Chile. Inaugurado como policlínico del Seguro Obrero, pasó a pertenecer al Servicio de Seguro Social en 1950 y luego como el Consultorio 2, en 1959 (Figura 6). Por su parte, el moderno Consultorio 1, en calle Nataniel Cox, apareció en los años cincuenta como una apropiada respuesta a las demandas de salud. Adicionalmente, la estructura de salud pública se fortalecía con otros avances edilicios tales como el reemplazo del antiguo edificio de Toesca que por largo tiempo albergó al Hospital San Juan de Dios. Demolido en 1944 por fallas estructurales, inició su nueva construcción en 1945.

Acompañando a los centros de atención primaria, en términos edilicios surgió el hospital de planta concentrada y en altura, haciendo desaparecer los criterios de orientación y asoleamiento que habían guiado la disposición previa a la existencia de la penicilina. La creación de la Sociedad Constructora de Establecimientos Hospitalarios en 1944, contribuyó a consolidar esquemas urbanos y edilicios, asumiendo las condiciones impuestas por la incorporación de tecnologías médicas.

\section{Giro en el debate y cambios disciplinares}

En 1932, el antiguo Ministerio de Bienestar Social, pasó a ser Ministerio de Salubridad Pública; y Ministerio de Salubridad, Previsión y Asistencia Social, en 1936. En 1956, ya quedaría atrás el énfasis en la "higiene" al nominársele como Ministerio de Salud Pública y Previsión Social por algunos años, hasta adquirir la denominación actual a partir de 1959. Algunos médicos y ministros de esta cartera contribuyeron con sus ideas a las políticas urbanas de higiene y salud. Tal fue el caso del ministro Eduardo Cruz Coke, quien tras analizar las tasas de mortalidad en 1937, impulsó la medicina preventiva mientras promovía que la temprana investigación de enfermedades específicas tendría una influencia positiva en la salud de la población ${ }^{23}$. Por su parte, el discurso de Salvador Allende, Ministro de Salubridad en los años cuarenta, destacaba que la preocupación por las condiciones sanitarias reunía a diferentes sectores políticos y clases sociales, y enfatizaba la importancia del entorno en la salud ${ }^{24}$.

Desde una concepción curativa en los años veinte, la medicina se orientó hacia una aproxima-

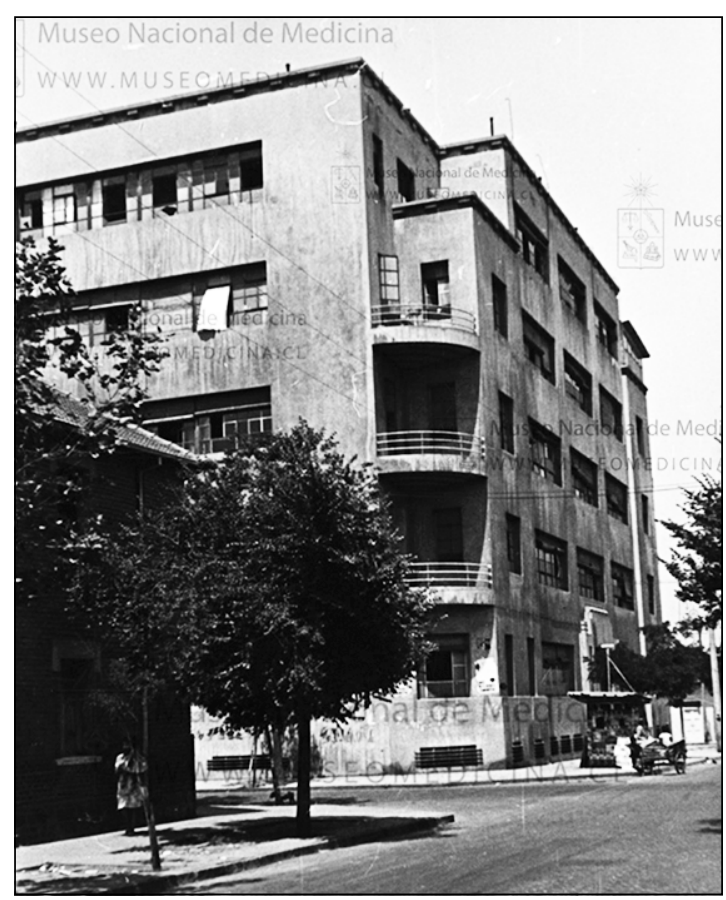

Figura 6. Consultorio Maruri, Santiago. Museo de Medicina Enrique Laval. 


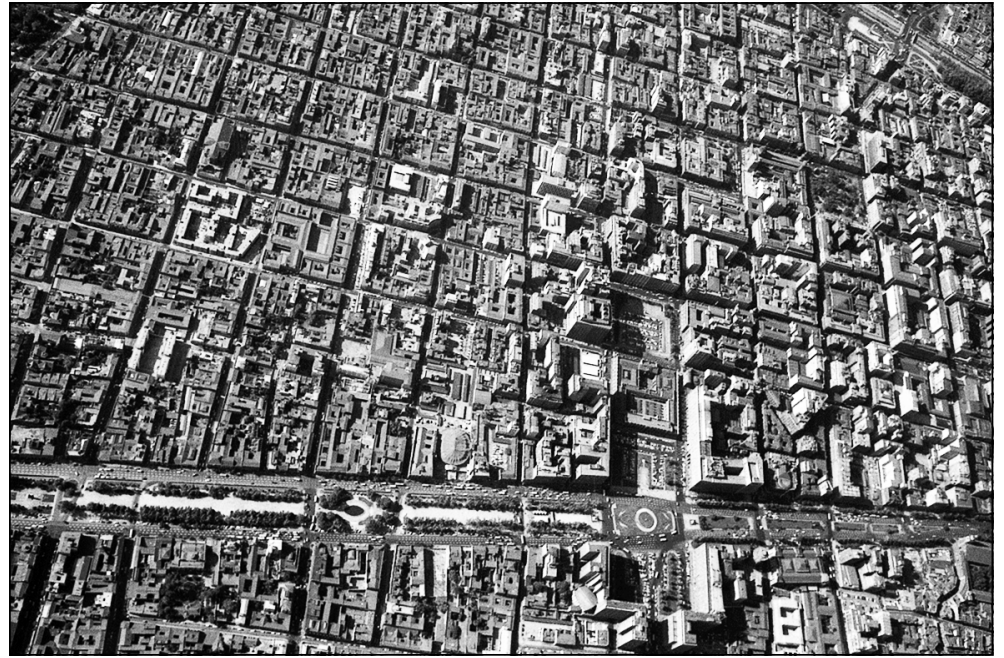

Figura 7. Vista aérea de Santiago en la década de 1960. Fotógrafo: Higinio González. Archivo visual de Santiago. ción social y preventiva. Resultado de lo anterior fue la vacunación para prevenir enfermedades infecciosas, la higienización, la extensión de agua potable y del alcantarillado, así como la obligación de usar máscaras para protegerse del polvo y de los gases tóxicos en las fábricas. Así, la medicina preventiva se articulaba con una ciudad cada vez más industrial. Posteriormente, en la década de 1940, una concepción epidemiológica comenzaría a imponerse en la organización racional de servicios de salud y en la estandarización de normas técnicas y administrativas para un adecuado servicio social y médico. Para ese entonces, el Estado concebía las mejoras en la salud como un camino para promover hábitos de limpieza, fomentar el cuidado de los niños y guiar a escolares y jóvenes en esta materia ${ }^{25}$.

Desde los años cuarenta, los arquitectos asumieron como prioridad la necesidad de expandir la infraestructura médica ante una ciudad de nuevas proporciones. Si bien en la construcción de infraestructura de la salud se requería de un trabajo colaborativo con urbanistas y planificadores, según señalaba el arquitecto Fernando Devilat, un contacto crucial fue la relación entre médicos y arquitectos a raíz del impacto negativo de las condiciones industriales tanto por la calidad de vida de los obreros como por sus efectos en la producción ${ }^{26}$ (Figura 7).

Los aportes de estos profesionales frente al problema de la higiene y de la salud pública de las ciudades chilenas, se vitalizaron al interior de sus propias asociaciones. La Asociación Chilena de Médicos (AMECH) en 1931 -antecedente del Colegio Médico, creado en 1949- se perfilaba como una organización de profesionales y como sindicato científico cuyo fin era coordinar la labor de los médicos y propiciar la formación de técnicos especializados.

Por su parte, la creación del Colegio de Arquitectos de Chile, en 1942, como cuerpo profesional con objetivos similares a las organizaciones gremiales que le habían precedido -la Sociedad Central de Arquitectos, el Instituto de Arquitectos de la Universidad de Chile y el Sindicato de Arquitectos de la Universidad Católica- se alineaba, entre otros, con la misión de "proyectar, dirigir y fiscalizar... (y elaborar) los planos de ciudades y barrios, parques y jardines y sus ampliaciones $\mathrm{y}$ reformas..." 27 .

Entretanto, reflejo de las tareas que iba consolidando el Estado a partir de los años treinta, el naciente urbanismo chileno se institucionalizaba y profesionalizaba mientras mantenía su atención en asuntos de higiene y salud pública. Para 1950, la población urbana en Chile había superado a la rural, y tanto el gobierno central como el local, se comprometían con nuevas fórmulas de planificación, intentando situar a Chile como un país moderno con una economía industrial y con una política que avanzaba hacia el Estado de Bienestar. 


\section{Referencias}

1. Instituto de Salud Pública de Chile. Historia del Instituto de Salud Pública de Chile (1892-2008): camino al Bicentenario Nacional. Santiago: Andros, 2008.

2. Almandoz A. Modernización urbana en América Latina. De las grandes aldeas a las metrópolis masificadas. Santiago: IEUT, 2013.

3. Almandoz A. Modernización urbana en América Latina. De las grandes aldeas a las metrópolis masificadas. Santiago: IEUT, 2013.

4. Ferrer PL. Higiene y Asistencia Pública, V Conferencia Sanitaria Internacional Americana. Santiago: Impr. Barcelona, 1911. p. 84.

5. República de Chile. El Ministerio de Higiene, Asistencia, Previsión Social y Trabajo. Ley reglamento y decretos que conciernen a su creación y organización. Santiago: Impr. La Tracción, 1926.

6. Larraín Bravo R. La higiene aplicada en las construcciones: alcantarillado, agua potable, saneamiento, calefacción, ventilación. Santiago: Cervantes, 1909. V. 1: v.

7. Caja de Crédito Hipotecario. Población Huemul. Inauguración de la sección beneficencia. Santiago: Soc. Impr. Litogr. Barcelona, 1918.

8. Larraín Bravo R. Programa del curso de Higiene aplicada a las construcciones profesado en la Universidad Católica de Santiago. Santiago: Impr. Cervantes, 1903. p. 8.

9. Mena Concha U. Programa del curso de Construcción profesado en la Universidad Católica de Santiago. Santiago: Impr. Cervantes, 1902. p. 8.

10. Calvo Mackenna J. Programa del curso de Saneamiento de las poblaciones profesado en la Universidad Católica de Santiago. Santiago: Impr. Cervantes, 1908. p. 14.

11. Dávila R. La higiene de la escuela. Santiago: Impr. Cervantes, 1884. p. 9-51.

12. Ríos T. La higiene i la escuela. Santiago: Impr. Cervantes, 1888. p. 14-15.

13. Ríos T. La higiene i la escuela. Santiago: Impr. Cervantes, 1888. p. 6.

14. Díaz E. Informe del médico-inspector de las Escuelas Públicas: presentado al señor Ministro de Instrucción Pública.
Santiago: Impr. Nacional, 1900. p. 34.

15. Díaz E. Informe del médico-inspector de las Escuelas Públicas: presentado al señor Ministro de Instrucción Pública. Santiago: Impr. Nacional, 1900. p. 34.

16. Rev. Instrucción Primaria 1910; 1-2: 5-6.

17. Salazar G. Pinto J. Historia contemporánea de Chile. Vol. 1. Santiago: LOM, 1999: 296; Walter RJ. Politics an Urban Growth in Santiago, Chile: 1891-1941. California: Stanford University Press, 2005.

18. Alessandri A. Mensaje leído por S.E. el Presidente de la República en la apertura de las sesiones ordinarias del Congreso Nacional, 21 de mayo de 1934. Santiago: Impr. Fiscal de la Penitenciaría de Santiago.

19. Estadísticas del Seguro Obrero. Declaración de principios de la AMECH, 1932. En Molina Bustos C. Orígenes de la Asociación Médica de Chile: una mirada crítica. Polis 2005 (4): 12. Disponible en http://polis.revues.org/ [consultado el 27 de junio de 2015].

20. En Molina Bustos C. Orígenes de la Asociación Médica de Chile: una mirada crítica. Polis 2005 (4): 12. Disponible en http://polis.revues.org/ [consultado el 27 de junio de 2015].

21. Ríos JA. Mensaje de S.E. el Presidente de la República en la apertura de las sesiones ordinarias del Congreso Nacional, 21 de mayo de 1945. Santiago: Impr. Fiscal de la Penitenciaría de Santiago.

22. Conclusiones del Cuarto Congreso Chileno de Asistencia Social. Rev. de Asistencia Social 1935: (4).

23. Cruz Coke E. Discursos: política, economía, salubridad, habitación, relaciones exteriores, agricultura. Santiago: Nascimento, 1946: 432.

24. Allende S. Plan de acción gubernativo. Bol. Médico Social 1940; (5): 67-8.

25. Discurso presidencial Pedro Aguirre Cerda. Rev. de Asistencia Social 1941; (41): 262.

26. Devilat F. Informe del Departamento de Arquitectura. Boletín del Servicio Nacional del Salud 1958; (4):313-16.

27. Crea el Colegio de Arquitectos de Chile, Ley N ${ }^{\circ} 7.211$, agosto de 1942, Santiago: Biblioteca del Congreso Nacional de Chile. Disponible en http://bcn.cl/1qdbl [consultado el 21 de diciembre de 2015]. 